\title{
The Effect of Cognitive and Behaviour Therapies on Prison and Post-Prison Inmates' Psychological Adjustment, In Afokang Prison, Cross River State, Nigeria
}

\author{
${ }^{1}$ MRS. Elizabeth, G. Akpama (Ph.D) \\ Department of Educational Foundations Faculty of Education \\ Cross River University of Technology Calabar, Cross River State, Nigeria
}

\begin{abstract}
This study was an experimental (pre-test, post-test) groups design, and analysed to determine the effects of cognitive and behavioural therapies on the psychological adjustment of prison inmates, using the Afokang prison in Calabar South local government area of Cross Rivere State as the study area. Three null hypotheses were formulated to guide the study, while a total of 120 inmates (109 males and 11 females) were randomly selected from the present stock of Afokang prisoners numbering 1017 (1006 males and 11 females) in the study area. Before treatment, the inmates were randomized into 3 groups (40 each for cognitive, behavioural and the control group - 36 males and 4 females for groups 1 and 2, 36 males and 4 females for the control group). After treatment which lasted for 8 weeks, all the 3 groups were again subjected to post-test and the result compiled for data analysis. Data was analysed using the independent $t$-test analysis procedures. The result revealed that: there is significant difference between prison inmates treated with cognitive therapy and others who are not treated at all in their psychological adjustment; there is significant difference between inmates treated with behavioural therapy and those not treated at all in their psychological adjustment; prison inmates treated with cognitive therapy do not differ significantly from their counterparts treated with behavioural therapy in their psychological adjustment. It was discovered that inmates subjected to any form of therapy differ significantly from those who did not pass through any form of therapy in their psychological adjustment. It was concluded that behavioural and cognitive therapies significantly influence prison inmates positively in their psychological adjustment (particularly after imprisonment). It was recommended among others that prison inmates should be subjected to cognitive and behavioural therapies in other for them to function well in the society after serving their jail term. .
\end{abstract}

Key words: Adjustment, behavioural, cognitive, experimental, inmates, prison, psychological, therapy

Submitted Date 07 June 2013

Accepted Date: 15 June 2013

\section{Introduction}

Imprisonment is a legal confinement for individuals who violate laid down rules and regulations and are confirmed guilty of such charges in the law court. The laid down rules, ethics and regulations are acceptable standards individuals are expected to comply with, in order to enhance peaceful co-existence within the society. Imprisonment serves as a corrective measure meant to enhance positive change in behaviour. Thus, the prison can be likened to a formal school system filled with activities that are meant to change the lives of prison inmates for the better. Law offenders sentenced to imprisonment are under normal circumstances meant to have their lives within the prison environment rehabilitated to become healthy and useful to both themselves and the society (Bully, 2008; Loucks \& Zamble, 2000 and Ibrahim, 2009).

In Nigeria, studies have revealed that only few inmates who engage in spirituality during their prison confinement, experience positive change in behaviour. Most of the prison inmates rather develop diverse emotional and psychological problems; some of these problems include rejection and disintegration from family members who consider them as failures and disappointment to the family. Most inmates also consider themselves as failures and disappointment to the society (Chukwem, 2008; Chukwuelue, 2009). Prison inmates need psychological stability to bounce back and live meaningful and productive life after serving their jail terms. The prison environment should provide emotional and psychological training for full adjustment of inmates.

However, most inmates experience adjustment problems due to some differences in culture and home background. The home and cultural influences create problems for them while they are confined in prison. Such inmates spend their time thinking and feeling depressed. Hagell (2002); Melgosa (2008) and Sorkin, Rook \& Lu (2002) observed that prison inmates who could not adjust to prison life due to cultural and home influences could not subject themselves to training within the prison environment. This hindered the psychological stability they needed to help them reason rationally and make well informed and realistic decisions. Their inability to get 
along with other inmates, prison environment and activities, further leads them into extreme depressive life. Hagell (2002) noted that some inmates with adjustment problems within the prison environment return to the society as they complete their jail terms with severe adjustment problems. Some who are not lucky enough to live and tell their stories die in prison custody out of depression.

Notably, the prison environment is comprised of inmates with various socio-economic statuses. Some of the inmates are highly educated, while others have little or no western education. Some of the inmates also have served the country in various capacities, while others have made no meaningful contribution whatsoever to the society. There are also other inmates who are perpetual law breakers and jail birds who feel that they have nothing to gain or lose either within the prison environment or outside the prison environment. These categories of inmates rather feel safer and are sure of their meals while in prison such inmates feel they have no adjustment whatsoever to make. Lipsey, Chapman and Landerberger (2001) and Haney (2001), noted that a blend of these people within the prison environment, together with the prison condition where the rooms are highly congested with inmates, is enough to cause emotional and psychological trauma to some inmates and also hinder successful adjustment.

There are cases where notable citizens who are in the upper class structure subject themselves to training within the prison environment in order to get themselves well adjusted to the situation they find themselves such inmates see the prison as a training ground especially where their hope for freedom is at stake. These are the likes of Nelson Mandela of South Africa and Olusegun Obasanjo of Nigeria, etc who subjected themselves to various reformatory conditions meted out to them (Cachalia \& Suttner, 2003).

On the other hand, there are also inmates of the upper class structure who are imprisoned due to some serious or minor negligence caused by them. Such inmates find it hard to forgive themselves and those who found them guilty and sentenced them to their various jail terms. Such inmates spend all their time in prison clouded with thoughts on how the society that held them in high esteem will regard them; wondering if they will be stigmatized when their jail terms are completed; how they can regain the confidence their family members had for them (especially their children and spouses). Such inmates never get themselves bothered about the prison environmental adjustment but they do bother about their psychological adjustment in their families and the society (Crocker, 2002; Ayllan \& Azrus, 1965).

Also, some inmates are sentenced to imprisonment on account of substance intake and trafficking. When individuals are unable to cope with life situations or when they are unable to provide solutions to pertinent problems, they resort to drug intake. Excessive drug intake plunge such individuals into undesirable behaviour that leads to their imprisonment. Narcotic drugs, such as heroin, cocaine, cannabis, etc. have several health consequences (Beck, 1991; Akinboye, 1992).

Prison inmates need to be exposed to cognitive and behavioural therapies in order to get them freed from psychological and emotional traumas. Training in these areas will assist inmates to think positively and enhance positive changes in them. Problems like drug and alcohol addiction require behavioural training while most cases that has to do with mental processes need cognitive training. There are also cases where inmates experience psychological and emotional problems that require training in the blend of both cognitive and behavioural therapies.

\section{Cognitive therapy}

Cognitive therapy focuses on the individuals' mind and thinking processes. It is believed that an individuals' behaviour is a reflection of the individuals' thoughts. A change in behaviour reflects the change in the individuals' thoughts. Negative thoughts provoke negative actions while positive thoughts provoke positive actions and consequences.

The aim of cognitive therapy is to instruct the individual to control his/her mind and thoughts in order to produce alternative ways of judging and behaving (Beck, 1991; Bandura, 1993; Mayer \& Salovey, 1993). For cognitive therapy to be effective, the individual must be able to identify, assess, block and initiate his thoughts as he wishes. Slow learners and the uneducated should be assisted to go through cognitive therapy with ease.

\section{Behaviour therapy}

Behaviour therapy deals with behaviour observation, identification of undesirable behaviour and modification of undesirable behaviour. Behaviour theorists opine that once an undesirable behaviour is identified and modified, the individuals' thoughts, values and feelings also changes. Behaviour therapy can best be used when the problems that require change are not deep rooted. It can be used for the following circumstances

i. To eliminate learned behaviour that is undesirable: In Nigeria, most prison inmates do not come out of prison modified as expected. Rather, they come out being worse in behaviour. This is because inmates learn undesirable behaviour from other inmates either by imitation or observation. Behaviour therapy can be used for such inmates if they must finish their prison terms and come out with modified behaviour. 
ii. When reward and prices are appropriate: The Nigerian prisons initiate various skills acquisition training to prison inmates. This programme is designed to equip inmates with various means of livelihood which will help them live functional lives as they leave the prison environment. The areas where inmates are trained include: carpentary and furniture making, tailoring, weaving, jewelries, barbing, hair dressing, crop farming, poultry farming, fish farming, etc. Rewards can be used as reinforcement to capture the attention of the inmates towards learning. This can go a long way to enhance the individuals' adjustment.

iii. When punishment is avoided: The Nigerian prison environment itself depicts punishment. This is further worsen when prison staff and the older inmates bully other inmates. In Afokang prison in Cross River State, inmates prefer day time to night time because of the dehumanizing nature and condition of the prison rooms. Inmates number 100 to 150 per room and the inmates take turns to sleep. Better prison condition can better the thoughts and behaviour of prison inmates. The issue of jail break will not arise in Nigerian prisons if the inmates are not dehumanized. The psychological adjustment of prisoners in and outside the prison environment can be effective when punishment of this nature is avoided.

iv. Desirable behaviour can be learned: Prison inmates who are imprisoned for various criminal offenses can receive behaviour therapy while in prison. This will help them to be socially adjusted and live modified life after their prison terms. Unemployment and joblessness can push an individual into criminality. Prison inmates can be counselled to take the skill acquisition training serious as it will help them function well outside the prison environment and also live redefined lives.

\section{The problem}

Nigerian prisons are overcrowded with inmates. Some of these inmates were confirmed guilty and sentenced to various jail terms. While some over the years are still awaiting trial, some have constituted themselves as jail birds. This means that such inmates despite the overcrowded nature of prisons take delight in being in prison. The overcrowded nature of the prisons has given rise to the various unhealthy and dehumanizing conditions experienced by inmates. This hinders adjustment processes both within the prison environment and the society after they had served their jail terms. The depressive, emotional and psychological trauma inmates go through turns most inmates into hardened criminals.

Despite the skill acquisitions training given to inmates to enable them function well in the society after serving their jail terms, most prisoners fail to avail themselves of this opportunity. They rather constitute themselves as "jail birds". Apart from the dehumanizing nature of Nigerian prison environment, other factors such as culture, punishment, poor feeding, etc contributes to inmates' emotional and psychological trauma. What most inmates experience in prison is alien to them and it contradicts their cultural beliefs and practices. It causes such inmates depression and mental torture.

Non recognition of class structure within the prison environment, send most inmates who belong to the upper class to their early graves rather than stay alive to narrate their prison experiences. Inmates of the upper class structure who had never been exposed to hard and hash conditions as experienced in prison, find it very difficult to adjust. This is because such inmates are not given preferential treatment but are forced to mix up with other prisoners. They are subjected to take their turns in sleeping and carrying out tasks. Such developments leave the inmates permanently depressed.

The researcher is worried about the alarming crime rate in the country even when criminals are aware that they stand to be imprisoned when caught. The researcher also wonders why most prisoners would prefer to return to prison after completing their jail term despite the dehumanizing condition of the Nigerian prison. The researcher is also poised to ask the following question: Is there any form of behaviour modification exercise within the prison circle? If the answer is yes, then why is the impact not felt? Prisoners come out of prison and put up behaviours that are worse than what took them to prison. The researcher therefore suggest the use of cognitive and behaviour therapies on Nigerian inmates to foster their psychological adjustment both within and outside the prison environment.

\section{Research hypotheses}

To give focus to this study, three null hypotheses were formulated:

i. $\quad \mathrm{HO}_{1}$ : There is no significant difference between inmates treated with cognitive therapy and others who are not treated with cognitive therapy in their psychological adjustment.

ii. $\quad \mathrm{HO}_{2}$ : There is no significant difference between prison inmates treated with behaviour therapy and others who are not treated with behaviour therapy in their psychological adjustment.

iii. $\mathrm{HO}_{3}$ : Prison inmates treated with cognitive therapy do not differ significant from their counterparts treated with behaviour therapy in their psychological adjustment. 


\section{Participants}

This study was carried out in Afokang prison in Cross River State. The participants were one hundred and twenty (120) inmates (11 females and 109 males). The choice of 11 female inmates was because there were not more than 11 female inmates in Afokang prison as at when this study was conducted.

The participants were randomly assigned to treatment. The experimental groups were exposed to cognitive therapy training and behaviour therapy training while the control group received no training. They were however compensated for taking part in the exercise.

\section{Research instrument}

The psychological well-being scale developed by Ruff (2002) was used as an instrument to measure the psychological adjustment of the respondents. The validity of the instrument was ascertained by two experts in measurement and evaluation in the Faculty of Education, Cross River University of Technology, Calabar. The test retest reliability of psychological adjustment scale was 0.711 . The instrument was administered to the participants at the beginning and after the training exercise.

\section{Procedure}

The study took place for eight (8) weeks. The experimental groups were trained once a week and spent 90 minutes for each contact. Topics covered during the period were on cognitive therapy and behaviour therapy. The researcher focused on discussion, lectures on cognitive and behaviour therapies, role playing, assignments. The researcher also used cognitive and behaviour techniques such as observation; identification of peculiar behaviour; self-talk; self-control; modelling; behaviour contracts, systematic densitization; cognitive restructuring; etc. The researcher interacted freely and indeptly with the participants as a means of creating an enabling environment for the participants to be sincere in their responses.

\section{Population and area of study}

The study was conducted in Afokang prison located in Calabar South Local Government Area of Cross River State, Nigeria. This prison which was established since 1978 has a capacity for 450 inmates (350 males and 100 females). This prison was originally created to house about 450 inmates, presently houses 1017 inmates representing 126 percent more than its designed carrying capacity. Thus, it was from the present number of 1017 inmates that the researcher randomly sampled 120 (109 males and 11 females) used for the study. Furthermore, of the total sample, 40 each (representing 33.3\% each) were randomly sampled to constitute the 3 groups (that is: 40 for cognitive, 40 for behavioural and 40 for control) of counselled inmates who were made to participate in the study.

\section{Data analysis and discussion of result}

At the end of the experimental exercise, generated data was prepared by coding/scoring and the scores extracted on to a table (items-by-persons table or data bank). It was from this data bank that the data were extracted, summarized into their means (x) and standard deviations (SD) and then subjected to statistical analysis of each of the hypotheses of the study using the independent t-test analysis procedures. The results are presented in tables 1,2 and 3 .

Table 1

Independent t-test analysis of difference in psychological adjustment of inmates treated with cognitive

\begin{tabular}{|c|c|c|c|c|c|c|}
\hline $\begin{array}{l}\text { Variable } \\
\text { Nature of therapy } \\
\end{array}$ & $\mathbf{N}$ & $\bar{x}$ & SD & df & t-cal & P-val \\
\hline Controlled group & 40 & 14.732 & 4.103 & & & \\
\hline $\begin{array}{l}\text { With cognitive therapy (exp. Group 1) } \\
\text { Total }\end{array}$ & $\begin{array}{l}40 \\
80\end{array}$ & $\begin{array}{l}17.831 \\
16.282\end{array}$ & $\begin{array}{l}3.062 \\
3.584\end{array}$ & 78 & 3.831* & .000 \\
\hline
\end{tabular}

* Significant at $\mathrm{p}>.05, \mathrm{df}=78$, crit-t $=1.968$ (2-tailed)

Table 2

Independent $t$-test analysis of difference in psychological adjustment of inmates treated with behavioural therapy and others not treated at all. $N=80$

\begin{tabular}{lcccccc}
\hline $\begin{array}{l}\text { Variable } \\
\text { Nature of therapy }\end{array}$ & $\mathbf{N}$ & $\mathbf{x}$ & SD & df & t-cal & P-val \\
\hline Not treated controlled group & 40 & 14.732 & 4.103 & & \\
& & & & & \\
& 40 & 16.844 & 1.160 & 78 & $3.135^{*}$ \\
Behavioural (experimental Group 2) & 80 & 15.788 & 2.632 & .001 \\
Total & & & & \\
\hline
\end{tabular}


* Significant at $\mathrm{p}<.05, \mathrm{df}=78$, crit- $\mathrm{t}=1.988(2$-tailed $)$

Table 3

Independent $t$-test analysis of difference in psychological adjustment of inmates treated with cognitive versus others treated with behavioural therapies $N=80$

\begin{tabular}{|c|c|c|c|c|c|c|}
\hline $\begin{array}{l}\text { Variable } \\
\text { Nature of therapy }\end{array}$ & $\mathbf{N}$ & $x$ & SD & df & t-cal & P-val \\
\hline \multicolumn{7}{|l|}{ i) With treatment } \\
\hline (a) behavioural & 40 & 16.844 & 3.062 & & & \\
\hline (b) cognitive & 40 & 17.831 & 1.160 & 78 & $1.22 *$ & .128 \\
\hline Total & 80 & 17.338 & 2.111 & & & \\
\hline \multicolumn{7}{|l|}{ ii) General scale } \\
\hline All treatment & 80 & 17.338 & 2.111 & & & \\
\hline Non-treatment & 40 & 14.732 & 4.103 & 118 & 3.778 & .000 \\
\hline Total & 120 & 16.035 & 3.107 & & & \\
\hline
\end{tabular}

* Significant at $\mathrm{p}<.05, \mathrm{df}=118$, crit-t $=1.968$ (2-tailed)

(for general, not significant for treatments)

\section{Results interpretation}

From all the three tables displayed (that is Tables 1, 2 and 3), it can be observed that all the calculated t-values of (1) $3.831 *$ for cognitive therapy versus non cognitive therapy; (2) $3.135^{*}$ for behavioural therapy versus non-behavioural; and (3) $3.778 *$ for general therapeutic treatments versus non-treatments, all were found to be greater than the critical t-value of 1.968 , needed for significance at 0.05 alpha level with 78 and 118 degrees of freedom. However, from table 3, the calculated t-value of $1.220 *$ for cognitive versus behavioural treatments, was found to be lower than the critical t-value of 1.968, at 78 degrees of freedom. With these results, the following interference evolved:

(i) From Table 1, there is significant difference between prison inmates treated with cognitive therapy and others who are not treated in their psychological adjustment. Those who are subjected to cognitive therapy exhibited (by their mean scores) better/higher psychological adjustment than others who did not receive any treatment.

(ii) From table 2, there is significant difference between prison inmates treated with behavioural therapy and those not treated in their psychological adjustment. Those treated exhibited higher mean scores than others not treated and as such those treated professed to exhibit better psychological adjustment than others not treated.

(iii) From table 3, prison inmates treated with cognitive therapy do not differ significantly from their counterparts treated with behavioural therapy in their psychological adjustment.

(iv) From the same table 3, the result number ii portrayed that on the general scale inmates who are subjected to all forms of psychotherapy profess to significantly differ in their psychological adjustment than other inmates not exposed to any form of treatment.

\section{Discussion of findings}

The statistical analysis of hypothesis one of this study has revealed therapy is significant difference between prison inmates treated with cognitive therapy and others who are not treated at all in their psychological adjustment. Here it was further exposed that those treated with cognitive therapy are able to adjust better psychologically (as portrayed by their higher scores) than their counterparts who are not treated with cognitive therapy. Such inmates exhibited low mean scores in their response pattern to research investigations. These findings are in agreement with Bully (2008), Haney (2001), Ibrahim (2009) and Cachalia and Shuttler (2005), who all argued that skill acquisition training helps the inmates to cope with prison conditions. Cognitive therapy it was discovered helped the inmates who passed through this therapy to reason and function realistically. The respondents also affirmed that cognitive therapy frees their minds from thoughts and helps them in their psychological adjustments.

The results of the statistical analysis of hypothesis two of this study have revealed that there is significant difference between prison inmates treated with behavioural therapy and those not treated at all, in their psychological adjustment. Those who are not treated with any therapy profess to find it difficult to adjust psychologically (based on their low mean scores) than their counterparts who are exposed to treatment. These findings are also in agreement with Crocker (2002); Loucks and Zamble (2000); Melgosa (2008); and Akinade (2012) who agreed that behaviour therapy will help inmates to put up behaviour that will be accepted within and outside the prison environment. The study also revealed that inmates who were subjected to behavioural therapy showed remorse for their maladaptive behaviour that led to their prison terms. They craved to live lives that will portray them as good citizens.

The statistical analysis of hypothesis three of this study have revealed that prison inmates treated with cognitive therapy do not differ significantly from their counterparts treated with behavioural therapy in their psychological adjustment. The results however, revealed that a significant difference exists between those treated with cognitive and behaviour therapy and those not treated at all, in their psychological adjustment. 
These revelations are in consonance with Bully (2008); Gotlieb (2004); Lipsey, Chapman and Landerberger (2001), who opined that cognitive and behavioural therapies changes the individuals' life for the better. In one of the follow-up visits to Afokang prison, the researcher discovered that those inmates treated with both cognitive and behavioural therapy adjusted psychologically to the prison environment.

\section{Counselling implications}

The findings of this study calls for the following counseling implications:

1. The essence of the use of cognitive and behaviour therapies on inmates is to create or give prisoners sense of belonging. To determine the effectiveness of these therapies on prison inmates, there should be followup on these inmates to ensure that those affected are fully adjusted in life.

2. Certificate of attendance or participation should be given to those with mastery on skill acquisition. This can help them to secure employment in private enterprises (for those who cannot establish on their own).

3. Government should employ the services of guidance counsellors to organize programmes on behaviour modification for the prison inmates.

4. Prisoners should be counselled to know the significance of going through these therapies and taking their trainings serious.

5. Religious or spiritual counselling should also be encouraged in prison homes. This is because there are some prisoners who are imprisoned for offenses they did not commit. To such prisoners, it takes spiritual counselling to build their faith and trust in God.

6. Government should build more prison homes in order to decongest the overcrowded prisons such as Afokang prison in Cross River State.

7. Government should improve on the conditions of the prison and its environment. The feeding and sleeping arrangement of prisoners should be looked into.

\section{Conclusion}

This study used Afokang prison as a case study to determine the effectiveness of using cognitive and behaviour therapies to aid prisoners' psychological adjustment within the prison and after their prison terms. Several reasons were enhanced as causing the prisoners emotional and psychological trauma. Chiefly among these reason is the dehumanizing nature of the prison environment. The findings of this study revealed that cognitive and behavioural therapies can be helpful to both the prisoners and the society. This is because during and after the prison terms, prisoners can adjust psychologically, thereby causing behaviour change from negative to positive. On this note, government was adviced to better the living conditions of inmates in order to enhance positive and desirable change in prisoners.

\section{References}

[1]. Akinade, E. A. (2012). Modern behaviour modification: Principles and practice. Ibadan: Bright Ways Publishers

[2]. Akinboye, J. O. (1992). Behaviour therapy and other treatment strategies. Ibadan: Paper Back Publishers Ltd.

[3]. Ayllan, T. \& Azrus, N. Y. (1965). Measurement and reinforcement of behaviour psychotics. Journal of Experiment Analysis Behaviour. 8, 357-358.

[4]. Bandura, A. (1993). Perceived self efficacy in cognitive development and functioning. American Psychologist. 28 (2), 117-148.

[5]. Beck, A. T. (1991). Cognitive therapy. American Psychologist. 46 (4), 368-375.

[6]. Bully, EQHome (2008). Beat crime, antisocial behaviour, bullying, abuse and mobbing with emotional intelligence. (EQ) (online) http://www.bully.com 16/08/08.

[7]. Chukwem, R. (2008). The hot house, life inside the prison. http://www.google.com

[8]. Chukwuelue, P. (2009). The nation's prison. Radio Nigeria Network News. June 20.

[9]. Crocker, J. (2002). The cost of seeking self-esteem. Journal of Social Issues (58), 591-615.

[10]. Hagell, A. (2002). The mental health of young offenders. Report commissioned by mental health foundation. Policy Research Bureau.

[11]. Haney, C. (2001). The psychological impact of incarceration: Implication for post-prison adjustment. http://aspe.nks.gov/hsp/derison2homeQshaney.com

[12]. Lipsey, M. W., Chapman, G. L. \& Landerberger, N. A. (2001). Cognitive-behavioural programmes for juvenile and adult offenders. A meta-analysis of randomized controlled intervention studies. Nashvile T. N.: Vanderbilt University Institution for Public PolicyStudies.

[13]. Ibrahim, M. (2009). A visit to Yola prisons. http://www.google.com

[14]. Loucks, A. D. \& Zamble, E. (2000). Criminal behaviour, violent behaviour and prison maladjustment in federal female offenders (on line) Applied Criminal Empirical Justice Review. Available: http://www.localhost.com 16/08/08.

[15]. Mayer, D. J. \& Salovey, P. (1993). The intelligence of emotional intelligence. Imagination, Cognition and Personality. 9 (3), 185211 .

[16]. Melgosa, J. (2008). Developing a healthy mind: A practical guide for any situation. Marid, Spain: Talleres Graficos Penalara.

[17]. Okoye, N. N. (2001). Therapeutic skills in psychology and counselling. Awka: Erudition Publishers.

[18]. Ryff, C. (2002). Scales of psychological well-being. Retrieved $5^{\text {th }}$ December 2006. cry@ dacstaff.wisc.edu.

[19]. Sorkin, D., Rook, K. \& Lu (2002). Loneliness, lack of emotional support, lack of companionship and the likelihood of having a heart condition in an elderly sample. Annals of Behaviour Medicine, (24), 290-300.

[20]. Cachalia, C. \& Suttner, M. (2003). A long walk to freedom: The autobiography of Nelson Mandela. South Africa: Nolwazi Educational Publishers (pty) Ltd. 